www.jmscr.igmpublication.org

Impact Factor (SJIF): 6.379

Index Copernicus Value: 71.58

ISSN (e)-2347-176x ISSN (p) 2455-0450

crossref DOI: _https://dx.doi.org/10.18535/jmscr/v6i4.109

Journal Of Medical Science And Clinical Research

IGM Publication

An Official Publication of IGM Publication

\title{
Preparedness and Performance of Health Care Workers Participating in Hajj season on the implementations of International health Regulations, Immunizations and Preventive health measures against Infectious diseases at King Abdul Aziz International Airport
}

Authors

\section{Dr Amal H. Al Ghamdi ${ }^{1}$, Dr Sultan A. Al Ghamdi ${ }^{2}$}

${ }^{1}$ Community Medicine Consultant, Post-graduate lecturer and trainer at The Saudi Board, Joint Program of Community

Medicine \& Preventive Medicine, Jeddah, Kingdom of Saudi Arabia

${ }^{2}$ Immunology and laboratory Consultant, Ministry of Health, Riyadh, Kingdom of Saudi Arabia

Corresponding Author

Amal H. Al Ghamdi

Community Medicine Consultant, Post-graduate lecturer and trainer at The Saudi Board, Joint Program of Community

Medicine \& Preventive Medicine, Jeddah, Kingdom of Saudi Arabia

\begin{abstract}
Background: The unique mass gathering of hajj represent substantial international public health burden with subsequent challenge for the health authorities in the host country. In this respect, Saudi Arabia, through updated comprehensive plan is providing preventive as well as curative services to more than two million pilgrims every season. To achieve this, a large number of health workers are moved to cover health services throughout the whole path of the pilgrims. Preparedness and compliance of the health workers to the guidelines are crucial for successful outcome. As there is paucity of researches in this era, the current study aim at assessment of the preparedness and compliance of the health workers at one of the main entry gates during hajj season in 1436 H /2015

Subjects and Methods: Through a cross section design, a sample of 112 health workers sharing work at King Abdul Aziz international airport during hajj were interviewed using semi structured questionnaire reflecting their preparedness to participate in work at airport as well as observing their compliance to guidelines while providing international recommended tasks.

Main Results: Most of the participants (88; 78.6\%) received recommended immunization before hajj, only one quarter of the participants previously attended training courses about international health regulations $(25 ; 22.3 \%)$ and personal preventive measure (33; 29.5\%). Their overall response to key items reflecting their preparedness to provide adequate preventive measures accounted for 55.5\%; the participants who attended training courses before hajj had significantly better achievements. All health workers were checking immunization cards for each pilgrim (111; 99.9\%), most of them were wearing gloves $(94 ; 83.9 \%)$ and only one half of them (56; 50.9\%) were fitting face masks properly.

Conclusion and Recommendations: Although that the participants showed fair preparedness to work in King Abdul Aziz international airport during hajj season, better achievement was observed among those who reported that they had received training courses about international health regulations and personal preventive measures before attending Hajj season, which calls for the necessity of future mandatory enrollment in such training courses for all health workers before sharing work in hajj.

Keywords: Preparedness, Performance, Health Care Workers, Immunizations, Preventive Health Measures, Infectious Diseases.
\end{abstract}

\section{Introduction}

Hajj is the largest annual religious mass gathering where more than two million Muslims from over
160 countries travel to Makkah at certain days of the year to perform their rituals ${ }^{(1)}$. Even though this enormous number of international travelers 
can introduce any infectious agents they may harbor $^{(2)}$, yet It is not only the number of pilgrims that matter, but also the wide variety of health risks which put the health authorities in the Kingdom of Saudi Arabia at a real challenge. Among the health risks, infectious diseases come on the top, as the pilgrims are usually coming from countries where a lot of endemic communicable diseases are prevalent ${ }^{(3)}$. To face this challenge, the ministry of health put annually updated preventive plan based on the conventional spread of communicable diseases worldwide. This plan is principally targeting prevention of imported infectious diseases ${ }^{(1)}$. In this respect, airports are considered as the frontier gates where proper international public health measures are likely to reduce the possibility of allowing the entrance of communicable disease to a country ${ }^{(4)}$. The King Abdul Aziz international airport is the main entry port for pilgrims which accustom 80.000 passenger at one time. About 600 employees of different jobs are recruited from the ministry of health, where they are designated at different parts of the airport including entry hubs. Health workers at the entry hubs are responsible for applying the International health regulations regarding screening of the pilgrims for certain recommended issues such as checking the immunization cards and ensure applying preventive medicines and immunization, in addition, pilgrims who are apparently ill are referred to be seen by a physician. Alongside, the health workers have to adhere to the recommended guidelines to protect themselves against acquiring any infectious diseases.

The role of health care providers at the hubs is critical. Despite its importance little had been done to ensure their performance, therefore the current study aim at evaluating preparedness of the participants to their tasks and the level of adherence to guidelines in their performance.

The study attempts to answer the following questions:

- Are the participants adequately prepared to apply the international health preventive measures as abide by the international health regulations?

- To what extent their performance achieve the screening of the coming pilgrims?

- Are they strictly adhere to guidelines regarding protecting themselves against potential hazards of communicable diseases?

\section{Subjects and Methods \\ Study Design}

This study is a cross-sectional study that was conducted during the pilgrims' arrival period between first and fifth day of Thul-Hija, 1436, at King Abdul Aziz International Airport, Saudi Arabia.

\section{Population of the study and sampling}

There are 14 hubs, which represent the first exit point for pilgrims, at each hub there are 6-13 health workers distributed proportionally according to the expected work load at each hub; making a total of 245 health workers. Each group is considered a team that constitute chiefly of at least one physicians and the rest are either nurses or health inspectors. To cover 24 hours work, there are two 12 hours' shifts; making a total of 28 shifts daily.

The sample size was based on assumption that the 0.5 of the participants were adequately prepared to take over work in the airport, with an acceptable level of variation \pm 0.05 , and at a confidence level of $95 \%$, the sample size accounts for 112 , which is almost one half of the total number of health workers.

To facilitate sampling and ensure the representativeness of different health workers' jobs, the selection was based on the shifts, as half of the population of study is required, one half of all the shifts was assigned randomly, as seven morning shifts and seven night shifts. All health workers in each shift were invited to be enrolled in the study.

\section{Tool of the study}

A semi-structured questionnaire was constructed to collect relevant data. The questionnaire included closed-ended as well as open-ended 
questions. It covers three main aspects, demographic characteristics, previous training such as attendance of training courses related to hajj, and adherence to self protective guidelines. The questionnaire was constructed in Arabic language and piloted on 20 individuals. All questionnaires were filled out during personal interviews. The interviews were conducted by the researcher and three trained assistants. Notes of the open-ended responses were taken while the participants were practicing at the hubs.

\section{Results}

Almost all participants at King Abdul Aziz international airport were Saudis $(96.4 \%)$, their mean age was $34.9 \pm 7.4$ years which ranged between 23-56 years; who were mainly had Diploma degree $(78.6 \%)$ with only one who had $\mathrm{PhD}$ degree. Health inspectors constituted more than one half of them $(54.5 \%)$ followed by nurses $(38.4 \%)$ while physicians formed only $4.5 \%$ of the participants [Table 1].

More than one half of the participants were recruited from Riyadh 63(56.3\%) followed by Jeddah $15(13.4 \%)$ while the rest were recruited from other areas such as Hail 9(8.0\%) Al Qaseem 7(6.3\%) and Dammam 7(6.3\%).

Regarding preparedness of the participants for sharing in services provided to pilgrims in the airport; as shown in [Table 2], it was realized that despite most of them $(78.6 \%)$ indicated that they received recommended immunizations for health workers sharing in hajj, and $72.3 \%$ reported that they passed training course about CPR, only one half of them $(55.4 \%)$ pointed that they had read about international health regulations and a much lower percentage $(22.3 \%)$ attended previously training course about these regulations. Less than one third of the participants $(29.3 \%)$ attended training courses about personal protective measures while dealing with crowd of pilgrims in the airport, and $40.2 \%$ of them received formal training about how to fix the face mask. As work with different parties in the international airport needs additional skills, the participants were verified for being prepared for such tasks; only one third of them (36.6\%) addressed that they had been acquainted about work in the airport before being enrolled in work, and few minority (13.4\%) said that they had attended training course about communication skills and how to deal with different parties in the airport.

To ensure preparedness of the participants for dealing with different recommended preventive measures, they were asked to respond on selected key aspects as shown in [Table 3]. Only one quarter of the participants $(25.9 \%)$ knew that the first thing to think about when facing a possible case of Ebola is the hand hygiene, and only one half of them $(52.7 \%)$ who knew that the last to be taken off after finishing a preventive task is the gloves.

Despite that the majority of the participants knew that all pilgrims from all over the world should be screened for possible meningitis cases $(82.1 \%)$ and those who are proven that they hadn't take the vaccine should receive Ciprofloxacin (83.9\%). Only less than one half $(43.8 \%)$ who knew that Ciprofloxacin is given as a measure to control for the carrier state and prevent transmission to other pilgrims, while one third of the participants thought that it is given as a replacement for immunization against meningitis. On the same line, slightly more than one half of the participants $(54.5 \%)$ knew that there is no need for giving meningitis vaccine for unvaccinated pilgrims who are coming from the African girdle when arriving at the airport.

Similarly, one half of the participants (48.2\%) thought that for pilgrims who are coming from polio endemic areas, only children who should be vaccinated at the airport.

Although Rifampicin intake is not included under the Saudi guidelines for preventive measures provided to pilgrims at airport; almost one half of the participants $(46.4 \%)$ thought that it is recommended measure to protect against cholera in adults. The same apply on Ceftriaxone intake which is not included in the guideline, yet, $41.1 \%$ 


\section{JMSCR Vol||06||Issue||04||Page 658-666||April}

of the participants thought that it is given to children to protect them against meningitis.

The right answers of the nine items reflecting knowledge of the participants about these items were summed up with one score for each right answer making a total of 9 . The overall mean score was $5.1 \pm 1.4$ out of 9 making an average level of knowledge of $55.6 \%$. To investigate the impact of previous training and attendance of courses, [Table 4 ] shows that the participants who had attended courses about international health regulations, and those who attended courses about personal protective measures and how to apply face mask before coming to Hajj season had significantly better knowledge than those who indicated that they didn't attend such courses

Table1: Characteristics of the study group $(n=112)$.

\begin{tabular}{|c|c|c|}
\hline Characteristics & No. & $\%$ \\
\hline $\begin{array}{l}\text { Nationality: } \\
\text { Saudi } \\
\text { Non Saudi }\end{array}$ & $\begin{array}{c}108 \\
4 \\
\end{array}$ & $\begin{array}{c}96.4 \\
3.6 \\
\end{array}$ \\
\hline $\begin{array}{l}<30 \text { years } \\
30-39 \text { years } \\
40+\text { years } \\
\text { Mean } \pm \text { SD (Range) }\end{array}$ & $\begin{array}{r}30 \\
54 \\
28 \\
34.9 \pm 7.4 \text { years }(23-56) \\
\end{array}$ & $\begin{array}{l}26.8 \\
48.2 \\
25.0\end{array}$ \\
\hline $\begin{array}{r}\text { Qualifications: } \\
\text { Diploma } \\
\text { Bachelor } \\
\text { PhD } \\
\end{array}$ & $\begin{array}{c}88 \\
23 \\
1\end{array}$ & $\begin{array}{c}78.6 \\
20.5 \\
.9 \\
\end{array}$ \\
\hline $\begin{array}{l}\text { Physician } \\
\text { Nurse } \\
\text { Health inspector } \\
\text { Pharmacy technician }\end{array}$ & $\begin{array}{c}5 \\
43 \\
61 \\
3\end{array}$ & $\begin{array}{c}4.5 \\
38.4 \\
54.5 \\
2.7\end{array}$ \\
\hline
\end{tabular}

Table 2: Preparedness of the participants to serve in health related activities in the airport $(\mathrm{n}=112)$.

\begin{tabular}{|c|c|c|}
\hline Preparedness activities & No. & $\%$ \\
\hline \multicolumn{3}{|l|}{ Previous immunization: } \\
\hline Yes & 88 & 78.6 \\
\hline No & 24 & 21.4 \\
\hline \multicolumn{3}{|c|}{ Passed training course about CPR : } \\
\hline Yes & 81 & 72.3 \\
\hline No & 31 & 27.7 \\
\hline \multicolumn{3}{|c|}{ Read about international health regulations: } \\
\hline Yes & 62 & 55.4 \\
\hline No & 50 & 44.6 \\
\hline \multicolumn{3}{|c|}{ Attended training course about international health regulations: } \\
\hline Yes & 25 & 22.3 \\
\hline No & 87 & 77.7 \\
\hline \multicolumn{3}{|c|}{ Attended training course about personal protective measures: } \\
\hline Yes & 33 & 29.5 \\
\hline No & 79 & 70.5 \\
\hline \multicolumn{3}{|c|}{ Trained about fixing face mask: } \\
\hline Yes & 45 & 40.2 \\
\hline No & 67 & 59.8 \\
\hline \multicolumn{3}{|c|}{$\begin{array}{l}\text { Attended acquaintance course about work in King Abdul Aziz International airport during } \\
\text { Haij : }\end{array}$} \\
\hline Yes & 41 & 36.6 \\
\hline No & 71 & 63.4 \\
\hline \multicolumn{3}{|c|}{ Attended training course about communication skills: } \\
\hline Yes & 15 & 13.4 \\
\hline No & 97 & 86.6 \\
\hline
\end{tabular}




\section{JMSCR Vol||06||Issue||04||Page 658-666||April}

Table 3: Response of the participants to items reflecting their preparedness to specific situations $(\mathrm{n}=112)$.

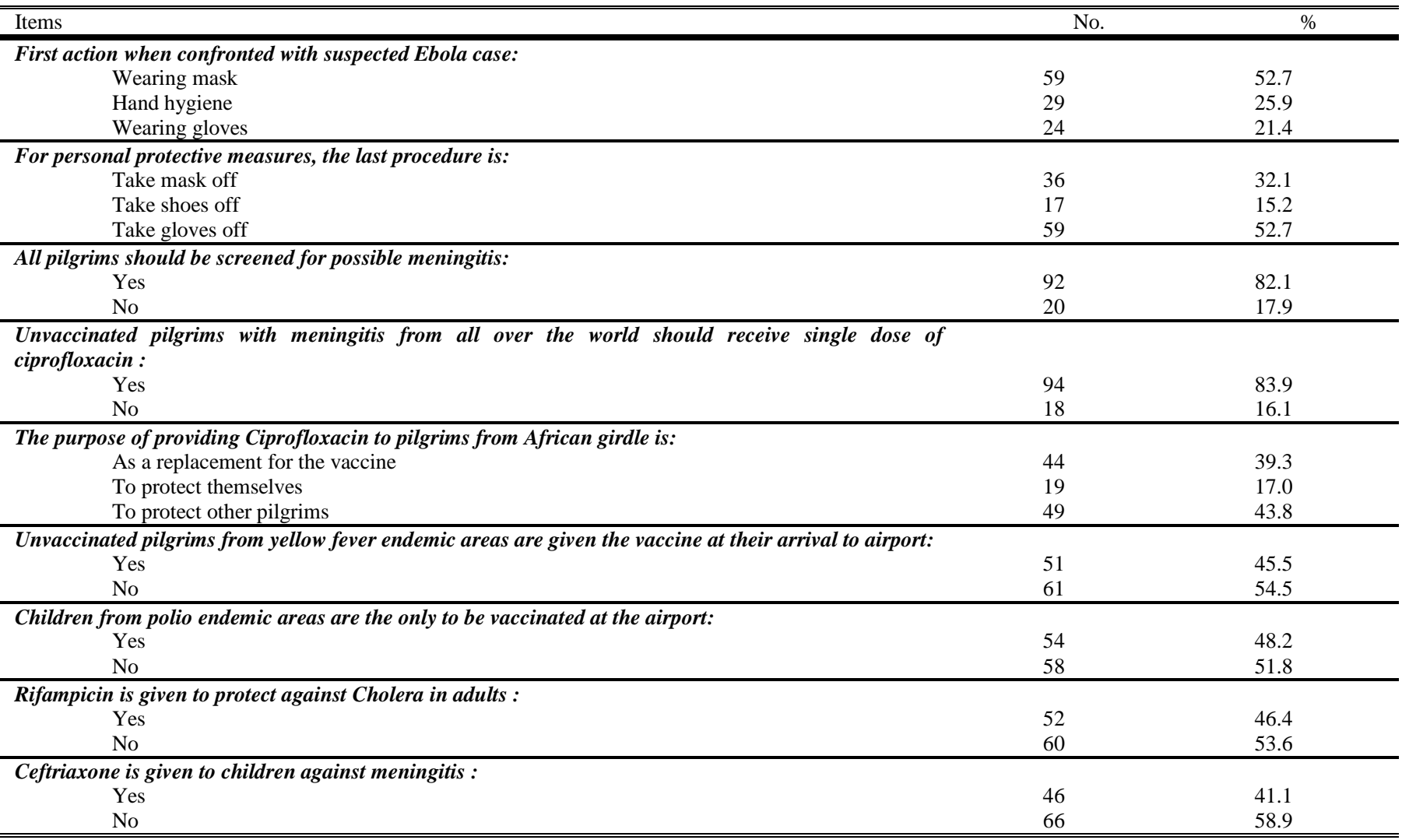

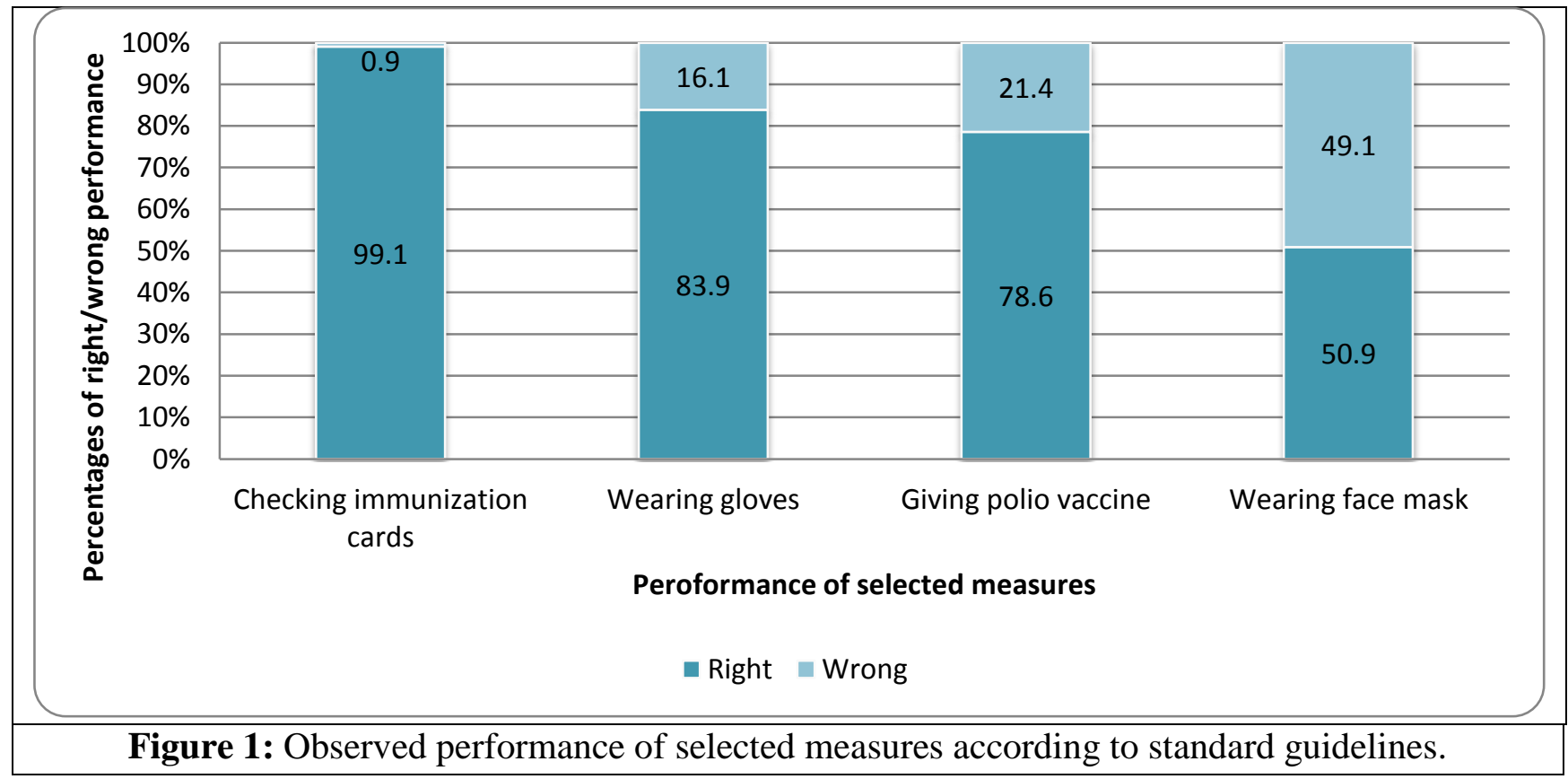

Table 4: Impact of previous reading and training about health regulations on the mean score of knowledge about items reflecting their preparedness $(n=112)$.

\begin{tabular}{lcc}
\hline \hline \multicolumn{1}{c}{ Previous training activities } & Mean \pm SD. & $\mathrm{P}^{*}$ \\
\hline Read about international health regulations: & & 0.837 \\
Yes & $5.1 \pm 1.5$ & $5.0 \pm 1.4$ \\
No & $5.8 \pm 1.7$ & $0.004^{* *}$ \\
\hline Attended training course about international health regulations: & $4.9 \pm 1.3$ & \\
Yes & & \\
No &
\end{tabular}




\begin{tabular}{lc}
\hline $\begin{array}{l}\text { Attended training course about personal protective measures: } \\
\text { Yes }\end{array}$ & $5.6 \pm 1.7$ \\
No & $4.8 \pm 1.2$ \\
\hline Trained about fixing face mask: & $5.6 \pm 1.5$ \\
Yes & $4.7 \pm 1.3$ \\
No & $5.4 \pm 1.7$ \\
\hline Attended acquaintance course about work in King Abdul Aziz International airport during & $4.9 \pm 1.3$ \\
Hajj: $\quad$ Yes & $5.1 \pm 1.5$ \\
No & $4.9 \pm 1.2$ \\
\hline Passed training course about CPR : & 0.075 \\
Yes & 0.446 \\
\hline \hline
\end{tabular}

\section{Discussion}

Hajj presents a significant challenge that impacts the international public health through potential risks of disease transmission and other health hazards. The Saudi Arabian authorities in collaboration with international bodies interested in this mass gathering are concerned with management of the hajj and the successful outcome of this event. In this respect, updated guidelines are established annually by the Ministry of Health, these guidelines are typically including two subsets of instructions. The first one is regarding measures towards pilgrims, and the second aim at protecting the service providers from acquiring any health hazards. These instructions are expected to be followed strictly, that necessitate preparing health workers before joining work at the airport and ensuring that they are fully compliant to these instructions. Among these instructions, all health workers who would share in hajj should be vaccinated against meningitis ${ }^{(5)}$ and influenza ${ }^{(6)}$. This obligatory instructions showed itself in the current study where most of the participants reported that they received the recommended immunizations.

Meningococcal disease outbreak are well recognized at hajj ${ }^{(7)}$; its risk increases during the hajj due to overcrowded, high humidity, and dense air pollution that could raise carrier rates up to $80 \%{ }^{(8)}$. For these reasons, the Saudi authorities stipulated mandatory immunization against meningitis for pilgrims. To check compliance of pilgrims to these instructions; their immunization status is checked properly by health workers at the entry ports. Pilgrims who have no documented immunization or invalid immunization in addition to those who are coming from highly endemic areas should receive compulsory oral ciprofloxacin $\left(500 \mathrm{mg}\right.$ ) to reduce carrier rates ${ }^{(9)}$. By validity of the meningitis immunization, it is meant that it must be taken at least ten days before arrival and no longer than 3 years before ${ }^{(5)}$. Although these procedures are performed routinely by our participants, only less than one half $(43.8 \%)$ of them knew the scientific background for giving ciprofloxacin.

According to the International Health Regulations, travelers from yellow fever endemic countries should present valid immunization certificate that the person had been vaccinated at least ten days before arrival and no longer than ten years ${ }^{(10)}$; otherwise they had to be put under strict surveillance for six days ${ }^{(11)}$, in contrary, about one half of the participants $(54.5 \%)$ thought that the alternative is to give the yellow fever vaccine.

Poliomyelitis is still prevalent in certain countries around the world, visitors from these countries to the hajj may pose a health risk for other visitors. All travelers from these countries; regardless of their age should receive one dose of oral poliovirus vaccine at least six weeks prior departure to Saudi Arabia; in addition, they also must receive another dose of OPV at borders' points on arrival in Saudi Arabia ${ }^{(1 ; 6)}$. Polio vaccination is essentially given to all travelers from endemic areas to develop herd immunity which is an important supplement to immunization ${ }^{(12)}$. One half of the health workers who knew that not only the children from the specified countries who should receive one dose of oral poliovirus at their arrival in the airport. 
Moreover, only one half of the participants were administering the vaccine properly.

The continuing threat posed by the Ebola virus in some African countries ${ }^{(13)}$ from which pilgrims might come for hajj, necessitate cautious preparedness; the committee on communicable disease prevention who felt that the risk of disease transmission is thought to be high with potential catastrophic consequences if occurring during the hajj ${ }^{(14)}$. In this context, the Saudi guidelines put strict rules for health workers based on the Personal Protective Equipment (PPE) guidelines (15), these guidelines include steps that must be followed accurately ${ }^{(16)}$. In this regards, only one quarter of our participants knew that hand hygiene come first before wearing gloves and fitting face mask.

Two items were included intentionally in the questionnaire although they are not listed under the regulations, the aim of its inclusion was to ensure acquaintance of the participants about the full list of the guidelines. The first one was about using rifampicin for control of cholera: although vibrio cholera is susceptible to rifampicin ${ }^{(17)}$, only one half of the participants knew that it is not one of the recommended preventive guidelines. Similarly, despite that ceftriaxone could be used for treatment of meningitis among adults ${ }^{(18)}$, yet, only one half of the participants realized that it not within the list as a measure for control of meningitis among children.

Generally, while observing performance of the participants, it was realized that the majority of them were wearing gloves but only one half of them were fitting face mask properly, in addition to what was remarked after summating their overall level of knowledge about the above selected items, it was revealed that their average knowledge was 55.5\%; could be attributed to lack of pre hajj formal training. This explanation is supported by the findings of the bivariate analysis which showed that the participants who attended training courses about international health regulations, personal protective measures and how to fix face mask before attending Hajj season had significantly better achievements than those who did not attend such courses.

\section{Conclusion}

Health care participants were fairly prepared to work in King Abdul Aziz international airport during hajj season, the better achievement observed among those who reported that they had received training courses about international health regulations and personal preventive measures before coming to participate in this season which pinpoint the significance of necessitate future mandatory enrollment in such training courses for all health workers before sharing work in hajj.

\section{Recommendations}

According to the study findings we recommend that all Health Care Workers Participating in Hajj season at King Abdul Aziz International Airport who perform preventive Measures on all Hajjes as approved and abide by the international health regulations should:

A. Before coming to King Abdul Aziz International Airport:

1- Complete all their vaccinations and deliver the (vaccination certificates).

2- Provide a certificate of attendance session of the definition of the procedures and policies adopted in the Airport by International Health regulations.

3- Provide a training certificate on Personal Protective Equipments.

4- Provide a training certificate on Fit Test.

5- Bring uniforms after taking the appropriate measures.

6- Attend an introductory course about communication skills.

B. After coming to King Abdul Aziz International Airport:

1- Attend an introductory session to King Abdul-Aziz Hajj Airport. 
2- Strictly adhere to the regulations of preventive measures at the airport.

\section{Reference}

1. Al-Tawfiq JA, Memish ZA. The Hajj: updated health hazards and current recommendations for 2012. Euro Surveill 2012;17(41):20295.

2. Alghamdi Amal H., Ibrahim Adel M., AlGhamdi, Mohammed S., Edward T. Travel Health in the Kingdom of Saudi Arabia: Perception and Practice of Saudi Travelers. International Journal of Health Research and Innovation, 2014 Jan 1;2(2):25-39.

3. Al-Tawfiq JA, Memish ZA. Mass gathering medicine: 2014 Hajj and Umra preparation as a leading example. International Journal of Infectious Diseases 2014;27:26-31.

4. World Health Organization. International Health Regulations 2005, 2nd ed. Geneva: The Organization. http://whqlibdoc.who.int/publications/200 8/9789241580410_eng.pdf . 2015. 1-12015. Ref Type: Online Source

5. Borrow R. Meningococcal disease and prevention at the Hajj. Travel medicine and infectious disease 2009;7(4):219-25.

6. Ministry of Health, Saudi Arabia. Health Regulations for Travelers to Saudi Arabia for Umrah\& Pilgrimage (Hajj)-1435 (2014). http://www moh gov sa/en/hajj/pages/healthregulations aspx 2015

7. Memish ZA. The Hajj: communicable and non-communicable health hazards and current guidance for pilgrims. Euro Surveill 2010;15(39):19671.

8. Al-Gahtani YM, El Bushra HE, Al-Qarawi SM, Al-Zubaidi AA, Fontaine RE. Epidemiological investigation of an outbreak of meningococcal meningitis in Makkah (Mecca), Saudi Arabia, 1992.
Epidemiology and

infection 1995;115(03):399-409.

9. Wilder-Smith A, Memish Z. Meningococcal disease and travel. International journal of antimicrobial agents 2003;21(2):102-6.

10. World Health Organization. International travel and health: situation as on 1 January 2010. World Health Organization; 2010.

11. Memish ZA, Al-Rabeeah AA. Health conditions of travellers to Saudi Arabia for the pilgrimage to Mecca (Hajj and Umra) for 1434 (2013). Journal of epidemiology and global health 2013;3(2):59-61.

12. Centers for Disease Control and Prevention (CDC). Epidemiology and prevention of vaccine-preventable diseases. Washington, DC: Public Health Foundation 2011.

13. Nyenswah T, Massaquoi M, Gbanya MZ, Fallah M, Amegashie F, Kenta A, et al. Initiation of a ring approach to infection prevention and control at non-ebola health care facilities-liberia, january-february 2015. MMWR Morbidity and mortality weekly report 2015;64(18):505-8.

14. Memish ZA, Al-Tawfiq JA. The Hajj in the time of an Ebola outbreak in West Africa. Travel medicine and infectious disease 2014;5(12):415-7.

15. CDC. Guidance for U.S. Laboratories for Managing and Testing Routine Clinical Specimens When There is a Concern About Ebola Virus Disease. http://www cdc gov/vhf/ebola/healthcareus/laboratories/safe-specimenmanagement html?utm_medium $=$ Email\&utm_source $=\mathrm{E}$ xactTarget\&utm_campaign 2015

16. Eurpean CDC. Safe use of personal protective equipment in the treatment of infectious diseases of high consequence. http://ecdc europa eu/en/Pages/home aspx 2015 
17. Seman M, Prok+íov+í M, Rosinsk++ J, Ferianc P. Isolation, identification, and characterization of Vibrio cholerae from the Danube River in Slovakia. Folia microbiologica 2012;57(3):191-7.

18. Nakajima H, Ota S, Hirose T, Hosokawa T, Ishida S, Kimura F. CeftriaxoneAssociated Cholelithiasis in Adult Patients with Bacterial Meningitis. J Infect Dis Ther 2014;2(161):2332-0877. 